\title{
Reference Decision Models in the Medico-social Service Sector
}

\author{
Henri Kromm ${ }^{1}$ and Yves Ducq ${ }^{2}$ \\ ${ }^{1}$ Acthan Expertises, 18 Rte de Beychac, 33750 \\ Saint Germain du Puch, France \\ hkrommaacthan-expertises.com \\ ${ }^{2}$ University of Bordeaux - IMS - UMR 5218 CNRS - 351 cours de la Libération - 33405 \\ Talence cedex - France \\ yves.ducqeu-bordeaux1.fr
}

\begin{abstract}
This paper aims at defining a dedicated method to analyse existing systems and to implement target models for social and medico-social structures in France. Based on GRAI Method, one proposes generic models for decisional systems and processes. The first application presented here proves that reference models could be used to identify strengths and weaknesses but also specific performance indicators more adapted than existing ones. The main observed results are an improvement of the added value of service and an optimization of strategic management tools. In a second time, we demonstrate that it is necessary to specify reference models for each kind of the 15 structures in order to take into account the people particularisms on one hand and to improve information system to answer efficiently to user needs and institutional requests on the other hand.
\end{abstract}

Keywords: performance indicators, business models, medico-social sector, modeling, decisional system, process models, quality management.

\section{The Medico-social Service Sector}

\subsection{Context}

The French social and medico-social service sector is governed by the Social Action and Family Code (Code d'Action Sociale et des Familles) revised in 2002 [1]. The L312-1 article [2] describes the organisation of the field, as well as its ad hoc actors. A typology of 15 potential actors can be drawn like: Institutions or departments usually dealing with young people under 18 or 21 , Institutions or special schools acting as main providers of adapted education and social or medico-social care to young people under 18, Health, welfare and social action centres, Institutions or departments implementing the educational measures ordered by Court concerning delinquents under 18 or under 21 , etc.

The field is made up of 35,000 structures and employs nearly three million people as well as volunteers and family caregivers in France. Since 2002 France has been engaged in a pro-active policy of professionalisation of the field which consists in: 
setting up long-term schemes (about disability, cancer, Alzheimer disease, etc),

$\checkmark$ favouring the empowerment of all actors involved through the tutelarization of structures, institutions and departments by specialized agencies: the National Agency for Performance (ANAP), the National Agency for Assessment (ANESM), Regional Health Agencies $(A R S) \ldots$

The whole medico-social service sector has integrated simultaneously the concept of continuous quality improvement, finding its main inspiration in the actions applied in the health sector.

\subsection{Issues at Stake}

The major issues are of two types. Firstly, the organisational challenges resulting from the complexity of medico-social structures. They are caused by the numerous processes implemented for the completion of planned activities and also by the nature of the service provided which affects the beneficiaries themselves in their personal fulfilment.

Secondly, the issue of management related to the very strong increase of requests by institutions to implement continuous quality improvement [3]. This includes the development of an assessment cycle combining self-assessment and external assessment by an independent organisation. The authorization for an institution to work depends on the completion of the whole assessment cycle which consequently influences the whole management of the structures.

Actually, numerous structures have kept traditional organisation methods and find it difficult to meet the expectations of/respond to requests by supervisory authorities [4].

The challenge of our work is thus to provide a method and a reference model for the implementation of a management structure adapted to the social and sociomedical service sector which could also integrate all its environmental evolutions. The objective is to build a reference model of the system which should lead to an implementation process associated to the ad hoc management tools (performance indicators).

\subsection{Structuring Measures and Reference Frames}

To support the different actors in their action, ANESM has created guidelines and recommendations in addition to the existing reference frames applying to each sector of activity. In fact, each federation, sector or grouping of structures has developed its own assessment tools in order to take into account the specific contexts and issues at stake for each of them: ISO Standards [5], the Angélique referential [6], the gerontology quality policy EVA [7], auto evaluation framework for public services [8], etc, are examples of the numerous evaluation tools and processes which can be used by the managers of socio-medical structures. In this context, it seems indispensable to move towards an harmonisation of reference frames in order to guarantee the quality of analysis and the homogeneity of results on the one hand, to facilitate the integration of the new standards and professional recommendations regularly emerging on the other hand. 
Besides, as aptly pointed out by [9], one confirms the necessity not to tend to reference frames (by sector or not), but rather toward operational models which take into account the type of users/beneficiaries, their needs and the specificities of the structure involved.

\subsection{The Medico-social Service System}

The classical production system [10] is characterised by: the resources which are going to carry out the transformation processes of the product, the products circulating in the system on which operations of added value are made, the issues of synchronisation and coordination of the availability of the resources and the products, an environment with a strong influence on the evolution of the system.

A number of strong specificities can be noted:

A very special customer: The customer is also a "product "of the system, if you consider the services provided as applying fully to their user. In fact, in some types of institutions (residential care homes, 'Etablissement Hospitalier pour Personnes Agées Dépendantes (EHPAD)' nursing homes, ...), the user is not necessarily supposed to get out of the place. Thus, as opposed to what happens in the education system, the user may have to stay permanently in the department. We can also consider the case of the users of medico-social services who, even if strongly encouraged to play an active role in their lives (through personalised projects for example), do not always have the capacities to become fully involved in their health paths [11].

\section{Very strong institutional and legal constraints}

Two categories can be considered:

1. Budgetary constraints as formalised in Tripartite Agreements and/or Aims and Means Contract (CPOM: Conventions d'Objectifs et de Moyens),

2. Constraints related to issues raising ethical concern such as the fight against mistreatment or the fight for the respect of the user's rights and freedoms.

These constraints shape all professional practices and lead to governance and management processes which are specific to the sector [12], [13]: evaluation cycles, activity traceability (healthcare and organised activities), etc.

One of the specificities is that some parts of the support activities are difficult to assess: the evaluation of the effectiveness of the actions relies on the analysis of the professional who undertakes them.

\section{Erratic flows}

The movements of the users are also quite specific. They are rare and connected to:

1. Either the necessity for a professional to intervene (e.g. operation) or the completion of a given action (e.g. catering/meals),

2. Either a choice from the user, sometimes with no particular objective, to move to a specific place as users called "outpatients" could do.

Indeed moves are often erratic and the issues of people's movement and logistics focus more on the safety of places and the observance of hygiene rules than on the optimisation of logistics flows themselves. 
Specific care: Healthcare for a user also requires assistance and safety at all times [11]. That is why institutions must constantly question their practices in order to guarantee optimal service quality, including when the user is in a more «private » area. In the health system, the main objective remains the recovery of the patient. Other objectives are contingent on the health system (pain relief, end of life care), but generally, the patient is meant to get out of the system cured. Concerning the users of the medico-social service system, if they can legitimately expect to come back to an ordinary background (home, workplace), they do not have the objective to be "cured" from their disability or to become younger. This fundamental aspect has a strong and double impact. First, it has an impact on activities for each profession: as opposed to what happens in the health system, the technical part of work is not always predominant, and the assistance and care to the users are generally more important than the sheer technical gestures that could be provided to them. Second, it has an impact on the professionals of the sector themselves who can quickly become worn-down by the impression that their work is ineffective. This second impact has a direct effect on the management methods used in the social and medico-social service sectors.

\section{Business Modelling Applied to the Social Sector}

\subsection{Method and Reference Decision Model}

Using the GRAI method [14], we consider the medico-social structure as an entity which connects the three classical subsystems.

The decision system offers the following functions in the basic version:

$\checkmark$ Managing human resources,

$\checkmark$ Managing infrastructures,

$\checkmark$ Managing accountancy and cash-flow,

$\checkmark$ Planning/ synchronizing.

Concerning the "activity-oriented" functions, we notice a recurrence of some functions such as:

$\checkmark$ Managing healthcare;

$\checkmark$ Managing organised activities and assistance;

$\checkmark$ Managing hospital accommodation and catering.

The physical system enables to model all activities (in the form of processes) implemented by a structure. Once again, the activities are usual ones and include all the skills of social workers, medical and paramedical staff: organised activities, psychology, healthcare, administration, etc.

Last, the information system is paramount when considering the growing issues of traceability of actions in terms both of how they are carried out and of which budget they are charged to. The typical decision grid (figure 1) for a nursing home can be found below: it is one of the reference models for decisional systems. The decisionmaking process is decentralised for the «activity-oriented » functions requiring specific skills (healthcare, organised activities, etc.). It remains centralised in the 
hands of institution management teams, particularly for the support and development functions (Human Resources, partnerships) as well as budget and reporting.

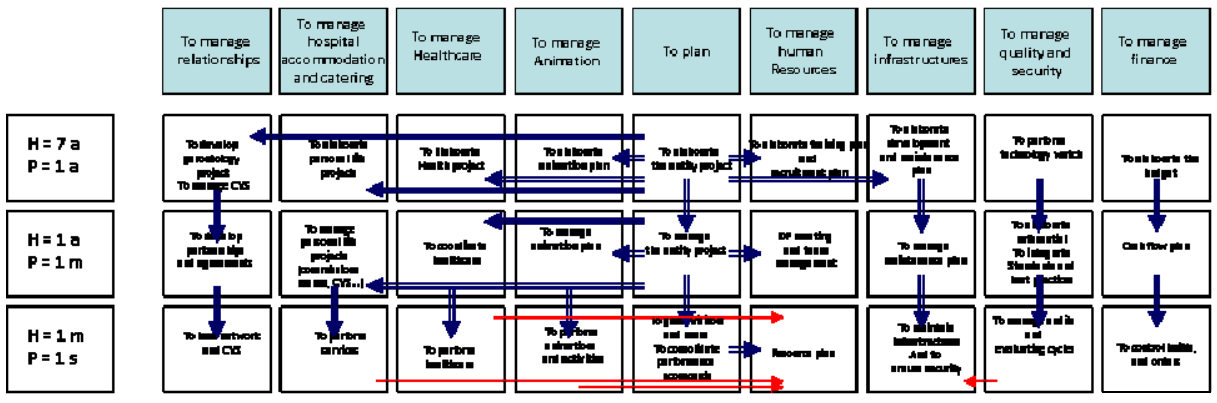

Fig. 1. The reference decisional GRAI grid for a nursing home

Long-term governance remains strongly bound to the environment of the system. Indeed, the development of institution relies on budget planning which is largely supervised by government-controlled organisations (Departmental Councils and Regional Health Authorities in particular). Budgets are closely connected to funding (subsidization) conditions for the institutions, and development strategies are consequently devised collaboratively with institutional partners.

The decision grid conceptualizes the monitoring of implemented processes, such as 'welcoming patients', 'providing care' for instance. Numerous models of processes were built based on GRAI diagram and GRAI actigram such as "welcoming process", or "emergency reception process.

Each step of the process is controlled by specific procedures. For example, we notice that the development of a personalised project is a fundamental step and that numerous documents rule this process: National Agency for Assessment (ANESM) recommendations, professional standards, etc. These reference models were used to specify action plans for the nursing home described here after.

\subsection{Management and Performance}

As a rule, governance relies on a certain number of indicators. The most well-known apply to the level of dependency (PATHOS tool) dealt with by the institutions:

PMP for Pathos Moyen Pondéré (PATHOS tool Weighted Average Dependency) [15] is a cost indicator in medical and technical care for a given population,

$\checkmark$ GMP for GIR (Groupe Iso-Ressources) Moyen Pondéré (AGGIR Weighted Average Autonomy) [16] is an indicator of the level of autonomy of a given population calculated by applying the AGGIR grid to each individual people in the group considered.

These indicators allow decision makers in particular to address supervisory authorities in order to negotiate the budgetary allocation keys and the aid amounts. After that, numerous indicators (statistics) make the answers to give to the authorities clearer, but we notice that institutions rarely read the results with enough precision to infer the relevant levers of action in terms of professional practices. 
1. About healthcare, we can mention: the number of bedsores, the number of injections, the average duration of care, by patient, etc.

2. For institutions providing accommodation: the occupation rate, the turnover rate, the checking out rate (with causes/justified), the depth of the waiting list, etc.

The indicators give results which are essentially statistics referring to specific activities. However, they are rarely put in perspective with the (often qualitative) objectives of the institution: the social culture of the sector is a natural restraint to this initiative. Besides, the indicators asked for by the institutions and the supervisory authorities being statistic indicators too, institution management teams often stop at this first level of performance assessment. The method of management is thus evolving towards a more budgetary approach, which creates tensions with the operational level which would prefer a user-centred type of management based on the quality of the service rather than financial aspects [17].

An indicator often required by supervisory authorities can be quoted as an example: the number and variety of partnerships signed by an institution. Yet we know that the number of partnerships does not prove the relevance of the cooperation and collaboration actions undertaken in comparison with the objectives pursued for the beneficiary. It seems more appropriate to use an indicator such as the "degree of activity of all the stakeholders for the benefit of a user": This enables to evaluate the relevance of undertaken actions contributing to mobilise professionals for the benefit of a user in order to maintain and/or improve his/her autonomy.

\subsection{Implementation Process}

The modelling of an institution applies following a classical modelling and development process in five steps:

1. Definition of objectives and goals,

2. Elaboration of existing system models,

3. Diagnostic of models,

4. Elaboration of target models,

5. Elaboration of action plan.

The modelling phase corresponds to a phase of abstraction which enables to translate the way an institution works, the way it is organised, and the processes it uses into understandable and analysable models. This analysis leads us to build an operating mode conceptualized by a set of models called 'target models'. The implementation of these models is conducted through a prioritized action plan.

Under no circumstances can this action plan be established on the sole and only basis of modelling, as the opinion and validation of the professional(s) involved is fundamental. The target models are used only for the justification of proposed actions and solutions.

\section{Application to the Case of an EHPAD Nursing Home}

We are applying this method to a public nursing home (EHPAD) of 55 beds. The level of dependency $(G M P)$ is of 783 and the level of medication (PMP) of 200. 
The institution is in a standard average according to the AGGIR and Pathos grids. In the context of the decree on external evaluation, this institution is making a request for external evaluation at the end of the self-evaluation conducted previously. The previous method was applied with some adaptations due to the specific context of legal external evaluation. One elaborates models of the physical system, called 'professional practices', the information system called 'organisation' and the decision system called 'management, cooperation and professional networks'. The figure 3 shows the process model for user welcoming.

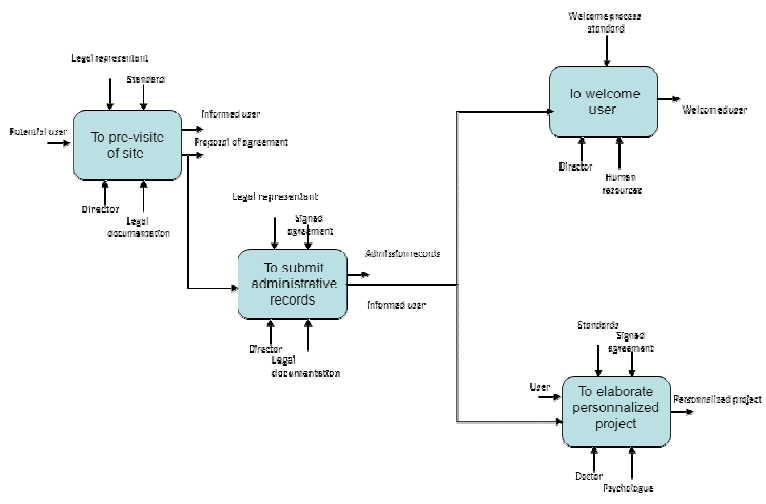

Fig. 2. Process model to welcome users

The analysis of models, based on specific GRAI rules, knowledge on best practices and ANESM guidelines, enables to establish a level of control over good practices for the different points and consequently to identify the areas for potential improvement. The analysis of the correlation between the means and needs shows a discrepancy between the resources available and the expectations: the growing number of internal projects has caused high expenses which have led to a mission drift for the professionals involved. As far as models are concerned, this results in too many functions for the same people: quality management (management of projects) and management of cooperation and external relations. This excess of roles to play generates a high activity which places a strain on the structure due to the growing mobilisation of professionals to the detriment of the closeness with beneficiaries.

Another way of analysis was the definition of specific indicators well-adapted to the nursing home such as well-feeling rating or dependency degree evolution. These indicators were consolidated into scorecard and adapted to each function described with the GRAI grid.

\section{Conclusions}

In this paper, we have defined the main characteristics of social and medico-social services organisations in order to put forward clear possible models. The implementation of the GRAI method enables to elaborate models specific to the different activities in this sector.

A set of models could be developed to demonstrate the applicability of the method to this context and the interest it represents to build specific reference models adapted 
to the type of users for these institutions. The creation of reference models for each sector constitutes a basis for the development of tools and methods to assist in the management of social and medico-social services institutions: systems of dedicated performance indicators, reference processes, guides of managerial and organisational good practices, adapted information systems, etc., are examples of tools that we will be able to define and implement. This leads us to think that there is a real opportunity of development and research in this evolving sector.

\section{References}

1. CASF-2002 - Code d'action sociale et des familles de, dernière version en vigueur, http: / / www. legifrance.gouv. fr/ (Octobre 29, 2011)

2. Loi 2002-2 de rénovation de l'action sociale et médico-sociale, http: / / www. legifrance.gouv. fr/

3. Loi Hôpital, Patient, Santé, Territoire du 22 Juillet 2009, http: / / www. legifrance.gouv. fr/

4. Décret 2007-975 du 15 mai 2007 fixant le contenu du cahier des charges pour l'évaluation des activités et de la qualité des prestations des établissements, http: / / www . anesm. sante.gouv. fr/

5. Blanc, D.: Santé et social: L'ISO 9001 à votre portée; Editions AFNOR (2008)

6. Gouley, C.: Evaluation de la Qualité: EVA, référentiel d'évaluation externe de la qualité des EHPAD. La revue hospitalière de France (2002)

7. Ministère de l'Emploi et de la Solidarité: Guide d'accompagnement de l'outil d'autoévaluation de la qualité en EHPA - Application ANGÉLIQUE (2000),

http://www.travail-solidarite.gouv.fr/

IMG/pdf/outil_auto_eval.pdf

8. European Institute of Public Administration: The common assessment framework: Improving an organisation through self-assessment. CAF resource Center (2002)

9. Ardoinot, J., Ladsous, J.: revue Lien Social, $\mathrm{N}^{\circ} 751$ rubrique rebonds (Avril 28, 2005)

10. Ducq, Y., Doumeingts, G.: Enterprise Modelling techniques to improve efficiency of enterprises. International Journal of Production Planning and Control 12(2) (2001)

11. ANESM: recommandation de pratiques professionnelles de l'ANESM - « Expression et participation des usagers dans les établissements relevant du secteur de l'inclusion sociale » (2008)

12. ANESM: recommandation de pratiques professionnelles de l'ANESM - « Mission du responsable d'établissement et rôle de l'encadrement dans la prévention et le traitement de la maltraitance $\gg(2008)$

13. ANESM: recommandation de pratiques professionnelles de l'ANESM - « Mise en oeuvre d'une stratégie d'adaptation à l'emploi des personnels au regard des populations accompagnées » (2009)

14. Ducq, Y., Vallespir, B.: Definition and aggregation of a Performance Measurement System in three Aeronautical workshops using the ECOGRAI Method. International Journal of Production Planning and Control 16(2) (2005)

15. Vétel, J.M., Leroux, R., Ducoudray, J.M., Prévost, P.: Le système PATHOS. La revue de gériatrie. Tome 24(6) (1999)

16. Aggir: Formulaire - Cerfa ${ }^{\circ} 11510^{*} 01$ disponible sur: http: / /vosdroits.service-public.fr/R21010.xhtml

17. Chemin, C., Gilbert, P.: L'évaluation de la performance, analyseur de la gouvernance associative. Politique et Management Public 27(1) (2010) 